\title{
Auditing in the Era of the COVID-19 Pandemic: A Discussion of Challenges and Key Matters
} Djoko Susanto

Professor

YKPN School of Business

Email: djokosusanto@stieykpn.ac.id

Indonesia

Adi Masli

Associate Professor and Koch Fellow

University of Kansas

Email: a059m271@ku.edu

USA

\section{ABSTRACT}

As of the beginning of November 2020, the number of COVID-19 cases worldwide has approached 47 million cases. In the United States, there have been over nine million COVID-19 cases, and the death toll is approaching 232,000 deaths. The pandemic has negatively affected the economy, unemployment rates, and the performance of many industry sectors. Despite the adversities of COVID-19, stakeholders need external auditors to continue providing high-quality assurance work. We discuss the challenges and key matters that external auditors face due to the pandemic. We provide thoughts and suggestions for auditors to consider. Additionally, we propose some research ideas for academic researchers to advance in the future. The topics that we emphasize include remote auditing, scope limitations, auditing inventory, disclosures on risks and uncertainties, subsequent events, going concern opinions, internal controls, and fraud risk. This article should be informative to audit practitioners, corporate stakeholders, and academic researchers. External auditing will continue to play a crucial role in the functioning of the capital markets. It is essential to gather and disseminate knowledge about how auditors can remain effective and resilient during even the most strenuous times.

\section{Keywords: Auditing; COVID-19; Pandemic}

\section{Introduction}

In late January 2020, the Director-General of the World Health Organization (WHO) declared the novel coronavirus (COVID-19) outbreak to be a "public health emergency of international concern," the highest level of alarm by the WHO. At the time, there were 98 cases and no deaths in 18 countries outside of China. ${ }^{1}$ As of the beginning of November 2020, the number of COVID-19 cases worldwide has approached 47 million cases. In the United States (U.S.), as of November 2020, there have been over nine million COVID-19 cases and over 231,000 deaths. ${ }^{2}$ To date, the U.S. reports the highest number of COVID-19 cases in the world.

According to numerous news outlets, the first confirmed COVID-19 case in the United States was reported in January 2020 in Washington state. By March 2020, COVID-19 cases were present in all 50 states within the U.S. ${ }^{3}$ As of the beginning of November 2020, the number of U.S. daily new cases averages approximately 81,000 cases, and the number of daily new deaths averages around 800 deaths. ${ }^{4}$ The COVID-19 pandemic has not affected the U.S. states and territories equally, as some states have reported significantly higher case rates than others.

The negative economic consequences of COVID-19 have been significant. According to the Bureau of Economic Analysis (BEA), the U.S. real gross domestic product (GDP) decreased five percent in the first quarter of 2020 (BEA 2020). The BEA also reports that U.S. GDP decreased at an annual rate of 31.7 percent in the second quarter of 2020. BEA (2020) also reports that corporate profits from current production decreased over $\$ 200$ billion in both the first and second quarters of 2020. Unemployment rates have also been adversely affected by the pandemic. In December 2019, Trading Economics (2020) reports that the U.S. unemployment rate was 3.5\%. In April 2020, the unemployment rate reached its highest annual level of $14.7 \%$. By August 2020, the unemployment rate declined to $8.4 \%$, yet still well above the $3.5 \%$ rate at the start of the 2020 calendar year.

The economic concerns of the pandemic can be gleaned from the 2020 PricewaterhouseCoopers (PwC) US CFO Pulse Survey, which reflects the perspectives of U.S. chief financial officers (CFOs) and finance leaders during the pandemic period. ${ }^{5}$ According to the April 2020 survey, the top 
concerns regarding COVID-19 and operating in a changing business environment were (i) negative financial impacts of the pandemic, (ii) potential of a global recession, (iii) negative effects on workforce productivity, (iv) decline in consumer confidence, and (v) supply chain disruptions. In June 2020, almost $80 \%$ of CFOs reported that their company was considering cost-containment implementations. More than half of the respondents conveyed that their company was deferring or canceling planned investments.

There has been a sharp rise in bankruptcy filings during the COVID-19 pandemic. Epiq (2020) reports that in the first seven months of 2020, Chapter 11 commercial filings are up $30 \%$ over the same period last year, with a total of over 4,000 filings. In July 2020 alone, commercial Chapter 11 filings were up 52\% over July 2019 with 642 new filings (Epiq 2020). Bankruptcy filings have not been confined to small and medium enterprises. Some of the largest and well-known companies, including Stein Mart, J.C. Penney, Neiman Marcus, Brooks Brothers, Hertz, and Chesapeake Energy,

have filed for bankruptcy protection during the pandemic period (Clifford and Wahba 2020).

Despite the devastating economic impact of COVID19 , some industry sectors have fared well during the pandemic. The sectors that have performed relatively well include online retailing (e.g., Amazon), takeout and delivery services (e.g., Uber Eats, DoorDash, Grubhub), online workspace solutions (e.g., Zoom, Citrix), supermarkets, hand sanitizing producers, online entertainment providers (e.g., Netflix) and liquor stores (Arora 2020). Also, CFOs believe that certain factors from the current adverse condition can help their company in the future. As reported in the $2020 \mathrm{PwC}$ CFO pulse survey, at least half of the CFOs expect that the pandemic situation will make their company better in the following dimensions: (i) more work flexibility; (ii) better resiliency and agility, (iii) new ways to serve customers, (iv) technology investments, and (v) leaner operations.

Auditing plays a crucial role in maintaining public trust in the capital markets (DeFond and Zhang 2014). Despite the uncertainties and challenges of the current pandemic, auditors need to remain effective and continue to provide highquality assurance work. In April 2020, Sagar Teotia, Chief Accountant of the U.S. Securities and Exchange Commission, reiterated the need for high-quality financial reporting in light of COVID-19. ${ }^{6}$ In the following section, we discuss the challenges and key matters that external auditors face as a result of the pandemic. We offer some suggestions for auditors to consider. Also, we offer ideas and questions that academic researchers can tackle in future research studies. The topics we highlight include remote auditing, scope limitations, auditing inventory, disclosures on risks and uncertainties, subsequent events, going concern opinions, internal controls, and fraud risk.

\section{Auditing in the era of the COVID-19 pandemic \\ 2.1. Remote auditing}

Traditionally, audit fieldwork involves a team of auditors physically working at the client's location (i.e., headquarter, office locations, etc.). As a result of the pandemic, many auditors have primarily been working from home and unable to travel to client sites i.e., remote auditing or virtual auditing. The concept of remote auditing is not new. With the growth of new technologies, such as cloud computing, digital devices, teleconferencing, and data sharing software, auditors have performed at least some form of remote auditing even before the pandemic. However, the scale or magnitude of remote auditing has increased significantly in today's pandemic environment. For many auditors, they have had to adjust their work procedures and communication processes quickly to fulfill their obligations. Working remotely at home can bring positive effects for auditors. For example, auditors would spend less time traveling to a client site and have more time working on the tasks at hand. The time saved from traveling would also increase the opportunity for the auditor to communicate with the client and co-workers.

Before the pandemic, some of the largest audit firms have already begun investing heavily in digital technologies. These technologies are likely instrumental in assisting auditors during the current time. For example, in 2017, Ernst and Young (EY) touted artificial intelligence as a technology that will transform the audit. ${ }^{7}$ The audit firm gave an example of lease accounting. Traditionally, analysis of lease accounting is conducted mainly using human review. EY advocated that artificial intelligence tools allow the analysis of a larger number of lease documents in a much shorter timeframe and less human involvement. The firm's pilot program showed that artificial intelligence would make it possible to review about $70 \%-80 \%$ of a simple lease's contents electronically. In 2016, Deloitte and IBM announced the Deloitte LeasePoint solution, also designed to streamline workloads toward compliance with new lease accounting regulations.

More recently, PwC in 2019 launched a multibilliondollar upskilling program called New World, New Skills, which supports PwC employees with the tools, training, and technologies needed to advance their audit work. One of the firm's technology is Cash.ai, a program that uses artificial intelligence to automatically process client documents, including reported cash balances, bank documents, and foreign exchange data to do a more comprehensive audit of cash (Cohn 2020). Another technology by the firm is the Aura Execution Engine, which is a cloud-based technology that streamlines the audit process by using artificial intelligence to make initial selections, validate data, and flag exceptions 


\section{(C) Center for Promoting Education and Research (CPER) USA}

www.cpernet.org

(Cohn 2020). These digital technology investments have been valuable in today's remote auditing environment by automating human labor and streamlining the auditors' work procedures. However, expansive digital technology initiatives have likely been executed mainly by the large audit firms. Given the significant IT investment costs, small and medium audit firms are less likely to take advantage of large scale digital technology tools during this pandemic.

The remote auditing has generated challenges for audit firms of all sizes. One of the critical challenges is the sharing and communication of documents between the auditor and the client (Shneyder 2020). In a remote audit environment, the client needs to give the auditor access to corporate documents, invoices, and statements. Some companies have used cloudbased technology to store their data, which gives the auditor remote electronic access to the information needed to conduct the audit. However, other companies continue to store all their data and software on their in-house hard drives and servers. In these cases, the auditor and the client need to work together and create creative solutions. For example, the auditor and client can build a temporary secure web portal to share data during the audit process. Regardless of the method, the communication channel ought to be conducive for both parties, and auditors need to be cognizant of the security of electronic data transfers. Weak cybersecurity can exacerbate the loss and corruption of information vital to the audit process (Shneyder 2020).

By auditing remotely, auditors heavily depend on video conferencing technology (e.g., Zoom) to communicate with clients and co-workers. Daily, auditors would spend hours in front of a computer (or other devices) video conferencing with other parties. There are a couple of issues that auditors ought to be aware of. The first issue relates to exhaustion due to excessive video conferencing or "Zoom fatigue." Fosslien and Duffy (2020), in their Harvard Business Review article, illustrate some reasons for "Zoom fatigue." First, video calls compel us to focus more attentively to keep up with the conversation and absorb information. Second, various workfrom-home situations (e.g., distractions from family members) can present challenges and disruptions to video call meetings. Some people simply miss in-person interactions with others, which contributes to video call exhaustion. Finally, "Zoom fatigue" can result from how one processes information over video i.e., continually staring at the computer screen and camera, which can be uncomfortable and tiring over a long period. Fosslien and Duffy (2020) provide research-based tips on how to combat "Zoom fatigue", including avoid multitasking, build in breaks in between video calls, reduce online stimuli, make virtual social events voluntary, use phone calls or e-mail as alternatives, avoid defaulting to video when possible.
The second issue with video conferencing relates to security. The act of video-teleconferencing hijacking or "Zoom bombing" is quite rampant nowadays, which refers to instances when unwanted participants enter a video conference meeting to disrupt the conversation. This act can be relatively harmless, where someone breaks into a conversation and plays a joke or a prank. However, the risks stemming from "Zoom bombing" can be more serious. Unwanted visitors can steal proprietary and sensitive information. The seriousness of this act has even caused the U.S. Federal Bureau of Investigations (FBI) to issue a public warning about teleconferencing hijacking during the pandemic. The FBI has recommended the following steps for video teleconferencing: (i) make meetings private, (ii) provide the link directly and securely to specific people, (iii) manage screen-sharing options, (iv) ensure users are using the updated version of the application, and v) ensure that the organization's policy addresses physical and information security. ${ }^{8}$

\subsection{Scope of limitations}

PCAOB AS 3105 on departures from unqualified opinions and other reporting circumstances discusses scope limitation issues. Paragraph 5 of this standard states that "restrictions on the scope of the audit, whether imposed by the client or by circumstances, such as the timing of his or her work, the inability to obtain sufficient appropriate evidential matter, or inadequacy in the accounting records, may require the auditor to qualify his or her opinion or to disclaim an opinion. In such instances, the reasons for the auditor's qualification of opinion or disclaimer of opinion should be described in the report." In this case, the auditor has to make a judgment about how scope limitations materially affect the financial statements. Common examples of scope limitation issues include the inability to observe physical inventories, lack of confirmation of account receivables from customers, and the inability to obtain financials from the investee to value long-term investments.

The COVID-19 pandemic creates scope limitation issues for the auditor. In the past, scope limitation concerns may come from the client e.g., the client restricting the auditor from communicating with customers to confirm receivables. However, in today's pandemic environment, the source of scope limitation concerns can stem from macro conditions and be beyond the control of the client or the auditor. As we discuss in more detail in the next section, auditors have been experiencing many challenges regarding physical inventory observations. Auditors may face difficulties communicating with the client's customers and cannot obtain confirmations of material account receivables. Unable to visit the client's location, the auditor may be unable to assess the design and implementation of internal controls comprehensively. 
Clients that lack sufficient technology infrastructure may have limitations in giving the auditor electronic access to documents and statements. Audit firms that lack digital technologies may not have sufficient resources for their audit team to conduct their audits effectively or efficiently. These issues are just examples as many more circumstances can create scope of limitation issues for auditors in this challenging environment.

Auditors need to keep in mind that when they qualify their opinion because of a scope limitation, the explanations in the opinion should suggest that the qualification pertains to the possible effects on the financial statements and not to the scope limitation itself (see paragraph 9 of PCAOB AS 3105).

\subsection{Auditing Inventory}

The issue of auditing inventory has been a hot topic during the pandemic. Traditionally, auditors would physically visit the client's facilities to observe physical inventory counting procedures and to conduct independent test counts of inventory. Stay-at-home policies and travel limitations during the pandemic, whether imposed by the organization or the government, have presented complications to auditing procedures over inventory. Clients may be unable to perform physical inventory counts at their locations due to the pandemic circumstances. Additionally, audit teams may be unable to perform their independent physical counts of inventory (i.e., in-person counting of inventory). If the client conveys that they need to lock down their inventory locations for some time, the auditor should investigate and confirm the client's testament. Confirmation procedures may include checking security camera footage of the client's warehouse(s) and reviewing logistics records for shipping and receiving activities (AICPA 2020).

AICPA AU-C Section 501 on audit evidence-specific considerations for selected items address specific audit considerations in obtaining sufficient appropriate audit evidence regarding inventory. Paragraph 11 of AU-C Section 501 states that if inventory is material to the financial statements, the auditor should obtain sufficient appropriate audit evidence regarding the existence and condition of inventory by attending physical inventory counting, unless impracticable to do so, and by performing audit procedures over the entity's final inventory records to determine whether they accurately reflect actual inventory count results. Paragraph. A34 of AU-C Section 501 allude to the condition that may make attendance at a physical inventory counting impracticable is if the location of the inventory is in a location that may pose safety threats to the auditor. The AICPA (2020) suggests that the COVID-19 pandemic may be considered a circumstance in which in-person attendance during physical inventory counting is impracticable.

So, what can auditors do if they cannot attend a physical inventory count? In this case, technology can help deliver a solution. Even before the pandemic, some audit firms have begun the development of drone applications for inventory counts. For example, Hermann Sidhu, CPA, Global Assurance Digital Leader at EY in a July 2018 interview with Courtney Vien (Journal of Accountancy) discussed the use of drones to enhance audits. He remarked:

"We would audit, for example, the world's largest retailers, big manufacturing companies, big pharma companies, who have permanent, massive warehouses. The ability to go and map the warehouse allows us then to have the drone fly autonomously without having a human auditor in the warehouse trying to fly a drone and being disruptive, potentially to the client... And similarly, you take that same concept outside. You know, we would have clients that have timber you know, mining clients, cars, automobiles. Another opportunity for the drone you know, once you have the area marked out, the drone can self-fly autonomously and be able to go scan barcodes, RFID codes, QR codes, OCR, etcetera."

During the pandemic, auditors can scale the use of drones to conduct remote inventory observations. Another method would be to have one or two trained personnel walk around the location and video record the counting. This method would limit the number of audit team members that would need to be on location physically. Concerning who should shoot the video recording, it would be advisable if it is not performed by a client employee involved in the inventory function (e.g., shipping clerk, receiving staff, etc.). Candidates for the function could include a member(s) of the audit team or staff of the client's internal audit. Many have also proposed using existing security camera systems to remotely observe inventory. With video technology, auditors need to be aware that there are limitations and risks by relying on video feeds. For example, one limitation with remote video is that the auditor may not be able to assess the condition or quality of the inventory adequately. The client may move the same inventory across multiple inventory locations (i.e., double-counting the same inventory), going undetected by security camera footage. Intending to mislead the auditor, a client may produce fake video footage of its inventory count. To the extent possible, auditors ought to rely more on live video feeds instead of prerecorded video footage.

For clients that use a cycle count procedure and a perpetual inventory system, the auditor can perform a rollforward procedure. In this case, the auditor can go to the latest cycle inventory count that was taken (before fiscal year-end) and then roll forward to year-end by using sales and purchase transactions that happened during the interval period. For the instances when the inventory count had to be postponed to a date after year-end, the auditor can conduct the roll-back 


\section{(c) Center for Promoting Education and Research (CPER) USA}

www.cpernet.org

procedure. Here, the auditor would count inventory at a later date and then take into account the sales and purchase transactions after year-end, effectively rolling back the inventory amount to the year-end.

\subsection{Disclosures on Risks and Uncertainties}

Financial Accounting Standards Board Accounting Standards Codification (ASC) 275 sets requirements about disclosures that pertain to risks and uncertainties that could significantly affect the financial statements. In particular, companies shall make disclosures in their financials about the risks and uncertainties in the following areas: (i) nature of operations, (ii) use of estimates in preparing the financials, (iii) certain significant estimates, and (iv) current vulnerability due to certain concentrations. ${ }^{10}$

The American Institute of Certified Public Accountants (AICPA) (2020) illustrates that the effects of COVID-19 may adversely affect significant estimates and worsen vulnerabilities due to certain concentrations. Paragraph 50-8 of FASB ASC 275-10 states that

"disclosure regarding an estimate shall be made when known information available before the financial statements are issued or are available to be issued ... indicates that both of the following criteria are met: (i) It is at least reasonably possible that the estimate of the effect on the financial statements of a condition, situation, or set of circumstances that existed at the date of the financial statements will change in the near term due to one or more future confirming events and (ii) the effect of the change would be material to the financial statements."

Hence auditors ought to evaluate the adequacy of management's disclosures about whether significant estimates used to form the financial statements may change in the near term due to future events connected with COVID-19. For example, management's estimate to calculate the allowance for doubtful accounts may change if the effect of COVID-19 worsens the financial viability of major customers.

Paragraph 50-16 of FASB ASC 275-10 states that

"vulnerability from concentrations arises because an entity is exposed to the risk of loss greater than it would have had it mitigated its risk through diversification... Financial statements shall disclose the concentrations described in...if, based on information known to management before the financial statements are issued or are available to be issued..., all of the following criteria are met: (i) the concentration exists at the date of the financial statements, (ii) the concentration makes the entity vulnerable to the risk of a near-term severe impact, and (iii) it is at least reasonably possible that the events that could cause the severe impact will occur in the near term."

Examples of concentrations, as described in FASB ASC 275-10-50-18, include the volume of business transactions with particular customers, revenue from certain products, and the availability of sources from key suppliers. For certain organizations, the COVID-19 pandemic materially affects these concentrations. For example, in light of the rise of business failures during the pandemic, the company may lose business relationships with particular customers. Such loss of customers will negatively impact future revenue and the ability to collect accounts receivables. The company may also lose business relationships with certain suppliers. In which case, the company will have difficulty sourcing materials, labor, or services, which leads to production difficulties.

FASB ASC 275-10-50-18 also describe concentrations about the market or geographic area in which the company conducts business. As described earlier, certain geographic regions are affected by the COVID-19 pandemic more severely than others. Therefore, if a company conducts a significant amount of business in these troubled areas, there are more significant considerations of risk and uncertainty that the company may need to disclose. The company's dependence on certain markets is also an important consideration. For example, if a company depends significantly on tourism or travel, some risks may warrant additional disclosures. In sum, auditors may need to perform additional scrutiny of company disclosures given the risks and uncertainties borne by the COVID-19 pandemic.

\subsection{Subsequent Events}

The auditor issues an opinion about the historical financial statements that present the company's financial condition as of that period's end date. However, auditors often time need to consider subsequent events, which are events or transactions that occur after the balance sheet date but before the issuance of the financial statements (see PCAOB AS 2801 Subsequent Events). Subsequent events can have a material effect on the financial statements and can therefore require an adjustment or disclosure in the financial statements.

Two categories of subsequent events require consideration by management and the auditor. As described in PCAOB AS 2801, the first type consists of those events that provide evidence about conditions that did not exist at the date of the balance sheet being reported on but arose after that date (i.e., nonrecognized subsequent events). These subsequent events should not result in any adjustment of the financial statements but may necessitate disclosure. ${ }^{11}$ An example of this type of subsequent event would be a loss of receivables because a customer suffered a sudden major casualty (e.g., fire) after the balance sheet date. 
The second type of subsequent event (PCAOB AS 2801) consists of those events that provide additional evidence concerning conditions that existed at the date of the balance sheet and affect the estimates inherent in the process of preparing financial statements (recognized subsequent events). In this case, the financial statements should be adjusted for any changes in estimates resulting from recognized subsequent events (AICPA 2020).

Currently, when the COVID-19 pandemic is still ongoing, this type of recognized subsequent event is relevant for numerous companies. For example, suppose there is a client with a balance sheet date of June 30, 2020, and a financial statement issuance date of September 15, 2020. The COVID-19 pandemic started before the balance sheet date and persisted even after the financial statement issuance date. Suppose the client had a business relationship with a major customer who suffered significant deterioration of operations due to the COVID-19 pandemic. A loss from an uncollectible receivable as a result of that customer filing for bankruptcy after the balance-sheet date and before the issuance of financials would suggest conditions existing at the balance sheet date, thereby requiring adjustments to the financial statements before their issuance.

\subsection{Going Concern Opinions}

The number of bankruptcy filings has significantly increased during the pandemic, which highlights going concern matters for auditors. PCAOB AS 2415 discusses the auditor's consideration of the client's ability to continue as a going concern. The PCAOB AS 2415 standard stipulates that the auditor has a responsibility to evaluate whether there is substantial doubt about the entity's ability to continue as a going concern for a reasonable period, not to exceed one year beyond the date of the financial statements being audited. In this evaluation process, the auditor's assessment is based on his or her knowledge of relevant conditions and events that exist at or have occurred before the auditor's report (PCAOB AS 2415).

If auditors do have substantial doubt, they will obtain information about management's plans to mitigate the effect of the adverse conditions and assess the likelihood of whether such plans can be implemented effectively. Ultimately, if the auditor continues to have substantial doubly, he/she would issue a going concern opinion. The issuance of a going concern opinion brings about one of the most contentious situation between the auditor and management. A going concern opinion can result in the financial demise of a company that would have survived if it had not received a GCO i.e., the "self-fulfilling prophecy" phenomenon (Carson, Fargher, Geiger, Lennox, Raghunandan, and Willekens 2013). Hence, management would try hard to resist and argue against a going concern opinion from the auditor. Nevertheless, auditors should maintain objectivity and use professional judgment to determine whether a going concern opinion is appropriate.

The COVID-19 pandemic has created adverse economic conditions and events that can create substantial doubt about a company's ability to continue business operations. However, this concern may not be the case for all industry sectors. As mentioned in the Introduction, various industry sectors have performed well during the pandemic. Hence, if the client is, for example, operating in the online retailing sector with increasing consumer demands, the pandemic environment will unlikely lead to the auditor having substantial doubt about the client's ability to continue as a going concern. Going concern matters are likely to arise when auditing clients operating in adversely affected industries, such as the hospitality, restaurant and bar, cruise ships, and airline industry sectors.

PCAOB AS 2415 illustrates certain conditions and events that auditors ought to consider when evaluating going concern matters. The following examples of circumstances may have been significantly impacted by the COVID-19 pandemic: operating losses and declining revenues, loss of key customers, working capital deficiencies, work stoppages, disruptions to production processed, cancellation of company projects, violation of debt covenants, a difficulty raising capital, dependence on geographic areas and markets severely affected by COVID-19, etc. Auditors must consider the cumulative effects of such conditions and scrutinize management's plans for dealing with the adverse conditions. Management's plans to combat today's economic adversity may include: selling assets, restructuring debt, borrowing money from lending institutions or government relief programs, issuing stock, reducing expenditures, and delaying investment projects.

When considering management's plans in dealing with the negative conditions, auditors need to pay attention to the underlying data and assumptions that enter management's projections. In today's environment, auditors need to be especially vigilant in their deliberations because there is a high degree of uncertainty with the pandemic (Dohrer and Tysiac 2020a). Auditors need to exercise professional skepticism when judging whether management's assumptions and forecasts are reasonable.

\subsection{Internal Controls}

PCAOB AS 2201 establishes the requirements and provides direction that applies when an auditor is engaged to perform an audit of management's assessment of the effectiveness of internal control over financial reporting that is integrated with an audit of the financial statements. As a result of the COVID-19 pandemic, there are many considerations that the auditor ought to assess as it relates to the client's internal controls. The structure and procedures of internal controls likely have changed as a result of the pandemic. 
The COSO Internal Control-Integrated Framework illustrates that internal controls consist of five integrated components: control environment, risk assessment, control activities, information and communication, and monitoring activities. Here, we provide some factors that auditors can consider when evaluating the effect of the pandemic on the client's internal control. The list of factors is not necessarily a comprehensive one but should provide some ideas for auditors to contemplate when assessing the internal controls.

1) Has the adversity borne from the pandemic affected employee morale? Has there been a downward shift in the organization's commitment to integrity and ethical values?

2) How has the board of director's/audit committee been able to carry out their oversight responsibilities during the pandemic? Has the inability to have inperson board/audit committee meetings affected their effectiveness? How often have they communicated with management?

3) Has the company lost key employees that have significant responsibilities over internal controls and financial reporting? Personnel essential to internal controls may have gotten ill from the virus or have suffered adversity during the pandemic.

4) As the pandemic has given rise to significant uncertainties and a challenging economic climate, how has the client identified and assessed its risks? Has the client bolstered its risk management system in response to the pandemic?

5) With the work-at-home condition, how do client employees process business transactions? What procedural changes have been implemented, and how have the internal controls been adapted? How do the design and implementation of internal controls postpandemic compare to the ones before the pandemic?

6) Has there been sufficient training for accounting personnel to work remotely? How well prepared was the accounting department to operate in the pandemic environment? Were employees able to have complete electronic access to important data and documents? Have employees been able to communicate with superiors, co-workers, and subordinates seamlessly about internal control matters?

7) Traditionally, the auditor would visit the client location to obtain an understanding of internal controls by interviewing employees, observing the workplace environment, and surveying the general operations of the accounting department. Given travel limitations during the pandemic, the auditor needs to creatively think of alternative methods to obtain a good understanding of the client's internal controls.
In sum, effective internal control is a crucial component of reliable financial reporting. Auditors need to consider how the pandemic has affected the efficacy of the client's internal controls. If one or more internal control material weaknesses exist, the auditor needs to express such concern in their opinion on the effectiveness of the client's internal control over financial reporting.

\subsection{Fraud Risk}

Another critical matter that auditors need to consider in this pandemic is fraud risk. The unfavorable conditions borne by COVID-19 can significantly elevate the fraud risk inherent in clients across industries and of all sizes. Three components can cause an individual to commit occupational fraud (i.e., the fraud triangle), which are perceived motivation, perceived opportunity, and rationalization (Cressey 1953; ACFE 2020).

In certain situations, the COVID-19 pandemic has increased motivation to commit fraud. As mentioned, many businesses were negatively affected economically by the pandemic. Executives may feel pressure to misstate their financials for the company to remain viable. If a company was close to violating a debt covenant agreement, managers might misstate financial results to avoid violating the covenant terms. CEOs of firms with cash shortfalls may manipulate the financials and showcase healthy accounting numbers to borrow capital from lenders. Corporate employees facing personal economic hardships due to the pandemic may have added motivation to misappropriate from the company.

There may be more opportunities to commit fraud because, as discussed in the previous section, internal controls may have changed or weakened during the pandemic. As an example, work-from-home conditions may have weakened the ability of internal auditors to monitor occupational fraud continuously. If the company needed to overhaul significant components of the internal control system due to changing working conditions, management might take the opportunity to override controls for personal benefit.

Finally, managers and employees may rationalize fraud during the pandemic. Executives could rationalize fraudulent actions by justifying that COVID-19 is not their fault, and they need to misstate the financials so that the company can survive through the adverse economic conditions. Employees could rationalize misappropriating assets by believing that they will pay the company back once things return to pre-pandemic conditions. Workers assigned to high-risk locations may feel underpaid, given that they are risking their health and expending more effort than other employees.

AU-C Section 240 addresses the auditor's consideration of fraud in a financial statement audit. Paragraph .12 indicates that the auditor should maintain professional skepticism throughout the audit, recognizing the possibility of 
fraud regardless of the auditor's historical experience with the integrity and honesty of the cleint's management and those charged with governance. This point is important for the auditor to keep in mind during current times. Before the pandemic (i.e., during normal times), the auditor may have had a favorable impression of the management's integrity and honesty. However, the auditor should maintain professional skepticism as the pandemic may have subsequently compelled management to make improper or unethical decisions. In other words, regardless of how positively the auditor viewed management in the past, the auditor should remain vigilant about management's conduct during these challenging times.

Paragraph .17(a) of AU-C Section 240 indicates that the auditor should make inquiries of management regarding the risk that the financial statements are fraudulently misstated, including the extent, frequency, and nature of such assessments. Further, paragraph .17(e) states that the auditor should inquire management about whether there have been any significant unusual transactions. In addition to inquiring management, the auditor would make inquiries of others within the entity to attain useful information about fraud.

One complexity for auditors to consider is that paragraph. A17 of AU-C Section 240 suggests that inquiries of management and other personnel are more desirable when they involve an in-person discussion. Given the pandemic, inperson interviews are often not plausible, which makes remote interview the best option. McGimsey and Lewis (2020) provide remote interview tips for auditors. They suggest some pros from virtual interviews, including reduced time and expenses for travel, easier and quicker to schedule the interview, and the ability to see the interviewee's face without a mask. At the same time, there are cons, which include the inability to search for physical evidence, more difficulty building rapport with the interviewee, and more limitations to observe nonverbal cues or body language (McGimsey and Lewis 2020). During these times, the auditor may opt to use a written questionnaire as a substitute for a face-to-face interview. However, the written questionnaire approach has certain limitations that the auditor needs to weigh. Most notably, auditors are unable to gather nonverbal signals or observe live reactions to the questions. Readers should read McGimsey and Lewis (2020) in more detail to learn tips for preparing for and conducting a virtual interview.

\section{Areas for Future Academic Research}

\subsection{Remote auditing}

In the area of remote auditing, it would be interesting for researchers to examine whether audit offices that invested more in digital technologies and training before the pandemic experience fewer disruptions in their audit procedures. Do audit offices with more experience with remote auditing techniques before COVID-19 produce better audit quality during the pandemic? For small and medium audit firms that are not able to invest significant amounts of money into digital technologies, how have they adapted to virtual auditing? Given the pros and cons of remote auditing, how has the pandemic changed the productivity levels of audit teams and individual auditors? Has remote auditing significantly reduced the scope and coverage of the audit to the detriment of audit quality? During the pandemic, is there a significant difference in audit quality between clients requiring a high degree of remote auditing work and those requiring less remote auditing? How have the adaptations that auditors needed to make affected the audit cost (i.e., audit fees)? How effectively have auditors been able to communicate and conduct audit brainstorming sessions with other members of the audit team? Are virtual meetings between the auditor and the audit committee equally effective as in-person meetings? These are examples of research agendas in the area of remote auditing that future researchers can consider.

\subsection{Scope of limitations}

In researching scope limitation issues, it would be worthwhile for researchers to study auditor disclosures and opinions issued during the pandemic period. How often are scope limitations a concern for auditors? During the pandemic, is there more variation in the types of opinions given by the auditor (i.e., qualified opinion, an emphasis of a matter paragraph, adverse opinion, disclaimer opinion)? How have audit teams dealt with the scope of limitation issues with their client? What categories of scope limitation issues do auditors cite? What client and auditor characteristics drive the disclosure of scope limitation concerns? Do auditors that have more expertise and resources address scope limitation issues more effectively than other auditors? These are just some examples of topics in the area of scope limitations that researchers could pursue in the future.

\subsection{Auditing Inventory}

For the topic of auditing inventory, future research should examine how auditors have coped with auditing inventory remotely. Which industries or types of clients rely more on remote inventory procedures? What alternative procedures to in-person inventory counting have worked the best for audit teams? Also, what non-traditional inventory counting methods have proven to be the most ineffective for auditors? Given the limitations of remote inventory audits, how have auditors assessed the valuation of the client's inventory (i.e., beyond just the existence of inventory)? During the pandemic, what proportion of audit failures or financial misstatements is due to incorrect inventory accounting? What auditor characteristics determine the cases of unreliable inventory evaluations? These are just examples of research questions in the area of auditing inventory that future studies can tackle. 


\subsection{Disclosures on Risks and Uncertainties}

Future academic research ought to examine company disclosures made during the pandemic. Using various textual analysis techniques, researchers can scrutinize the tone and substance of disclosures about uncertainties and risks. What role do auditors have in shaping the client's financial disclosures related to uncertainties and risks? How do auditors assess management's accounting estimates for high-risk accounts, such as allowance for doubtful accounts and intangible assets? Does the level of disclosure on COVID-19 uncertainties and risks have consequences on firm outcomes, such as cost of debt, credit ratings, shareholder activism, stock returns, analyst forecasts, etc? Researchers can also look into the disclosures by the auditor. Has the pandemic prompted auditors to discuss critical audit matters more fully? Do auditors offer more clarifications in the form of an explanatory paragraph or emphasis of matter paragraph? These are a few examples of research questions in the area of corporate disclosure that future studies can address.

\subsection{Subsequent Events}

COVID-19 has produced potential issues regarding subsequent events. Many companies with year-ends in the calendar year 2020 have pandemic-related subsequent events that may require financial statement adjustments and/or additional disclosures (AICPA 2020). Identifying subsequent events that involve the adjustment of the financial statements and/or disclosures requires the auditor to exercise judgment and to have knowledge of the relevant facts and circumstances. Research on the issues that the COVID-19 pandemic has inflicted upon subsequent events would be an interesting avenue of study. For example, future work can examine the auditor's judgment and decision-making process during the pandemic. How do auditors make decisions about COVID-19 related subsequent events that lead to management making adjustments to the financial statements?

\subsection{Going Concern Opinions}

The academic research on the auditor's going concern opinion is rich, as a plethora of research papers have already examined a wealth of determinants and consequences of going concern opinions (Carson et al. 2013). Nevertheless, there are ample opportunities for researchers to examine going concern decisions in the context of the COVID-19 pandemic. For example, which industries have been particularly susceptible to going concern decisions? Have auditors changed their materiality thresholds as they evaluate the substantial doubt about the client's ability to continue operations? Do auditors place more weight on particular financial ratios and/or nonfinancial information when making a going concern decision during the pandemic? How do auditors evaluate management's plans during a time when uncertainties are high, and audit work procedures have changed? Do management teams and audit committees push back harder against going concern opinions nowadays compared to the pre-pandemic period? Are auditors more sympathetic to management's struggles during the pandemic, which then compromises their objectivity? How have Type I (i.e., issuing a going concern to a client that survives) and Type II (i.e., not issuing a going concern to a bankrupt client) error rates changed during the pandemic period?

\subsection{Internal Controls}

There is a large stream of academic research on auditor reporting of the client's internal controls. Yet, future academic studies can do more to examine how auditors assess the client's internal controls during the pandemic. Given the pandemic, how have auditors revised the nature, extent, and timing of substantive testing over internal controls? With remote auditing, how do auditors observe and gain a thorough understanding of the client's control environment and tone at the top? What types of internal control material weaknesses are the most problematic during these times? With the transition to remote auditing, how effectively are auditors able to evaluate the client's internal controls? During the pandemic, do auditors place more weight on particular inputs when determining material weaknesses? Do auditors charge more fees and take longer to complete the audit given that pandemic may have compelled the auditor to assess internal controls differently? Given the adverse conditions, are clients able to remediate material weaknesses found before the pandemic? These are some research directions in internal controls that academics can take on in the future.

\subsection{Fraud Risk}

From an academic research perspective, there are many issues to study concerning fraud risk during the pandemic. For example, archival research ought to investigate the rate of financial misstatements during the pandemic period. How has the comparison between the rate of error restatements and fraud restatements changed compared to the pre-pandemic years? Are auditors less able to detect financial statement fraud during the pandemic? If so, what auditor characteristics are driving such audit failures? Are auditors relying on the client's internal audit function even more during the pandemic to detect fraud? How do auditors detect nonverbal cues when conducting virtual interviews? During the pandemic, are auditors more likely to resign from high audit risk clients compared to prior periods? What consequences do auditors face when their clients commit financial statement fraud during the pandemic? Are the consequences more or less severe compared to before the pandemic? These are a sample of research questions in the area of fraud risk that future research can address.

\section{Conclusion}

As the Center of Audit Quality (2020) notes, the COVID-19 pandemic continues to affect company financial statements in various ways and at differing severity levels 


\section{(c) Center for Promoting Education and Research (CPER) USA}

www.cpernet.org

depending on the organization's capitalization, the industry in which the business operates, and geographic location. The pandemic has also introduced challenges and changes to the auditing profession. In this article, we communicate the challenges and key matters that external auditors face during the pandemic. We also provide some suggestions for auditors to consider to maintain high-quality engagements during the pandemic. The topics discussed include remote auditing, scope limitations, auditing inventory, disclosures on risks and uncertainties, subsequent events, going concern opinions, internal controls, and fraud risk.

This article should be of interest to audit practitioners, corporate stakeholders, and academic researchers. Audit practitioners can consider some of the issues detailed in this article as they conduct audits during the pandemic. They may find some of the discussions and insights useful as they continue to maintain high audit quality during these uncertain times. This article will inform corporate stakeholders (i.e., management, audit committee, the board of directors, etc.) about the challenges and changes that the pandemic has created for external audits. Having this understanding will hopefully improve the stakeholders' engagement and interaction with external auditors. Finally, we hope that the discussions in this article can spur future research ideas for academic researchers to pursue.
This article primarily focuses on external auditing in the U.S. Clearly, COVID-19 is a global pandemic that has affected many countries worldwide. There are a couple of issues for consideration. First, many U.S. companies have foreign operations and subsidiaries. Given that the severity of COVID-19 and its effects differ across countries, future work should look into how auditors have coped with the unique challenges of having clients that operate multi-nationally. Second, the pandemic related issues discussed in this paper are likely not confined to just auditors working in the U.S. While the U.S. reports the highest number of COVID-19 cases, many countries are facing similar difficulties and struggles from the pandemic. We encourage researchers across the globe to report on the challenges and issues that auditors face due to the pandemic.

Finally, this article focuses on the effect of the current COVID-19 pandemic on auditing. However, the content and discussions herein can also be informative if other pandemics or widespread crises occur in the future. External auditing will continue to play a critical role in the functioning of the capital markets. We must continue to accumulate and disseminate knowledge about how auditors can remain effective and resilient during difficult times.

\section{References}

AICPA. 2020. FAQs - Audit Matters and Auditor Reporting Issues Related to COVID-19.

Association of Certified Fraud Examiners (ACFE). 2020. The Fraud Triangle. Available at: https://www.acfe.com/fraudtriangle.aspx. Accessed Sept. 12, 2020.

Arora. 2020. Which Companies did Well during the Coronavirus Pandemic. Available at:

https://www.forbes.com/sites/rohitarora/2020/06/30/which-companies-did-well-during-the-coronaviruspandemic/\#71ff220d7409.

Bureau of Economic Analysis (BEA). 2020. News Release. Available at: https://www.bea.gov/news/2020/gross-domesticproduct-2nd-quarter-2020-second-estimate-corporate-profits-2nd-quarter.

Carson, E., Fargher, N.L., Geiger, M.A., Lennox, C.S., Raghunandan, K. and Willekens, M., 2013. Audit reporting for goingconcern uncertainty: A research synthesis. AUDITING: A Journal of Practice, 32(Supplement 1), pp.353-384.

Center for Audit Quality. 2020. Auditor Reporting COVID-19 Considerations. A CAQ COVID-19 Resource.

Clifford, L. and Wahba, P. 2020. A Running List of Companies that have Filed for Bankruptcy during the Coronavirus Pandemic. Available at: https://fortune.com/2020/08/04/companies-filing-bankruptcy-2020-due-to-covid-list-filed-chapter-11coronavirus-pandemic/.

Cohn, M. 2020. PwC Showcases New Technologies. Accounting Today. Available at:

https://www.accountingtoday.com/news/pwc-showcases-new-technologies.

Cressey, D.R., 1953. Other people's money; a study of the social psychology of embezzlement.

DeFond, M. and Zhang, J., 2014. A review of archival auditing research. Journal of accounting and economics, 58(2-3), pp.275326.

Dohrer, B. and Tysiac, K.. 2020a. Going Concern Tips for Auditors during the Pandemic. Journal of Accountancy.

Epiq. 2020. Chapter 11 U.S. Commercial Bankruptcy Filings Up 52\% in July. Avaialable at: https://www.epiqglobal.com/enus/about/news/restructuring-bankruptcy/chapter-11-bankruptcy-filings-up-52-percent-july\#. 
Fosslien, L. and Duffy, M.W. 2020. How to Combat Zoom Fatigue. Harvard Business Review. Available at: https://hbr.org/2020/04/how-to-combat-zoom-fatigue.

McGimsey, C. and Lewis, N. 2020. Video Interview Tips for Forensic Accountants and Auditors. Journal of Accountancy.

Shneyder. 2020. Auditing goes Remote. Accounting Today. Available at: https://www.accountingtoday.com/opinion/auditinggoes-remote.

Trading Economics. 2020. United States Unemployment Rate. Available at: https://tradingeconomics.com/unitedstates/unemployment-rate. 